\title{
THE TRANSFORMATION OF SYNTHETIC HECTORITE IN THE PRESENCE OF Cu(II)
}

\author{
HÅkon Fischer ${ }^{1} *$, Peter G. Weidler ${ }^{2}$, Bernard Grobéty ${ }^{3}$, Jörg Luster ${ }^{4}$, and Andreas U. Gehring ${ }^{1}$ \\ ${ }^{1}$ Institute of Geophysics, ETH Zurich, 8092 Zurich, Switzerland \\ ${ }^{2}$ Forschungszentrum Karlsruhe, Institute for Technical Chemistry, Water- and Geotechnology, 76021 Karlsruhe, Germany \\ ${ }^{3}$ Institut de Minéralogie, Université de Fribourg, 1700 Fribourg, Switzerland \\ ${ }^{4}$ Swiss Federal Institute for Forest, Snow, and Landscape Research WSL, CH-8903 Birmensdorf, Switzerland
}

\begin{abstract}
The influence of $\mathrm{Cu}(\mathrm{II})$ on the hydrothermal and thermal transformations of a synthetic hectorite was investigated by a combined approach using mainly X-ray diffraction, thermal analyses, and electron paramagnetic resonance spectroscopy. The presence of $\mathrm{Cu}(\mathrm{II})$ during hydrothermal treatment increased the crystallite size. Copper (II) was both structure-bound and associated with the inner surfaces of the particles. Upon heating, structural destabilization of the hectorite began at $\sim 400^{\circ} \mathrm{C}$ as indicated by the formation of free radicals. Between 600 and $700^{\circ} \mathrm{C}$, the hectorite converted to enstatite, and in the presence of $\mathrm{Cu}(\mathrm{II})$, to enstatite and richterite. The formation of richterite as an additional conversion product is explained by the creation of structural weakness due to structure-bound $\mathrm{Cu}$ (II) in F-containing hectorite. Our results suggest that traces of $\mathrm{Cu}(\mathrm{II})$, typical of natural environments, may influence the conversion products in high-temperature geochemical systems.
\end{abstract}

Key Words-Cu(II), DSC, EPR, Hectorite, Hydrothermal Treatment, TG, XRD.

\section{INTRODUCTION}

Little is known of the effect of trace impurities, at average concentrations in geological systems, on the formation and transformation of layer silicates. Of particular interest in this respect is $\mathrm{Cu}(\mathrm{II})$, firstly because of its potentially significant structural effects due to preferred axially-distorted octahedral coordination, and, secondly, because it can be detected spectroscopically at low concentrations.

Hectorite is a Mg-rich trioctahedral smectite. It can be synthesized easily under hydrothermal conditions (Decarreau, 1980). Its thermal conversion to enstatite and cristobalite has been described in detail (Green et al., 1970). Few studies have investigated the effect of metal cations on the crystal growth of hectorite. Decarreau (1981) showed that, during synthesis, $\operatorname{Mg}(\mathrm{II})$ can be substituted by $\mathrm{Cu}$ (II) to a certain extent. This was confirmed for the co-precipitation of hectorite in the presence of $\mathrm{Cu}(\mathrm{II})$ during hydrothermal synthesis, while this was not the case if synthesized hectorite was reacted with a $\mathrm{Cu}(\mathrm{II})$ solution at room temperature (Spagnuolo et al., 2004). On the other hand, Mosser et al. (1997) postulated, based on electron paramagnetic resonance (EPR) spectra, that heating of $\mathrm{Cu}(\mathrm{II})$-exchanged hectorite to $\sim 200-300^{\circ} \mathrm{C}$ led to migration of $\mathrm{Cu}$ (II) into the structure, and offered the Hofmann-Klemen effect to explain this behavior. Mandair et al. (1990) reported that $\mathrm{Cu}(\mathrm{II})$-exchanged hectorite converts thermally to enstatite and an amorphous $\mathrm{Si}$ phase. The newly formed

\footnotetext{
* E-mail address of corresponding author:

hakon.fischer@mag.ig.erdw.ethz.ch
}

enstatite contained $\mathrm{Cu}(\mathrm{II})$ in its structure. To date, no investigations have reported the effects of traces of $\mathrm{Cu}(\mathrm{II})$ on the crystallinity and thermal conversion of hectorite.

The aim of this research was to demonstrate the effect of trace concentrations of $\mathrm{Cu}(\mathrm{II})$ on the crystallinity of hectorite under hydrothermal conditions, its thermal stability, and its conversion products, and to pinpoint the locations of $\mathrm{Cu}(\mathrm{II})$ in the hectorite and its conversion products.

\section{SAMPLES AND METHODS}

An industrially produced hectorite (Optigel SH, Southern Clay Products, Inc, Gonzales, Texas), characterized by a very fine grain size and a high degree of purity, was used for the experiments - its chemical composition, reported by Boukerrou et al. (2006), is $42.09 \% \mathrm{O}, 24.36 \% \mathrm{Si}, 15.82 \% \mathrm{Mg}, 1.6 \% \mathrm{Na}$, and $0.27 \%$ Li. In addition, $100 \mathrm{mg} \mathrm{kg}^{-1}$ of $\mathrm{Fe}$ and $440 \mathrm{mg} \mathrm{kg}^{-1}$ of $\mathrm{F}$ were found.

For the hydrothermal treatment, $0.2 \mathrm{~g}$ of $\mathrm{LiF}$ and a variable amount of $\mathrm{Cu}\left(\mathrm{NO}_{3}\right)_{2}$ or $\mathrm{CuCl}_{2}$, corresponding to $\mathrm{Cu}(\mathrm{II})$ concentrations of $0,50,150$, and $500 \mathrm{mg} \mathrm{kg}^{-1}$, were dissolved in $400 \mathrm{~mL}$ of deionized water. After adding $20 \mathrm{~g}$ of hectorite to the solution, the mixture was homogenized to a gel with a Turrax shear mixer. This gel was placed in Teflon-lined digestion bombs and incubated for $72 \mathrm{~h}$ at $180^{\circ} \mathrm{C}$. The treated gels were converted to powder form by drying at $65^{\circ} \mathrm{C}$, and are referred to below as $\mathrm{Cu} \_0, \mathrm{Cu} \_50, \mathrm{Cu} \_150$, and $\mathrm{Cu} \_500$.

The thermal evolution of untreated and hydrothermally treated hectorite powders between room temperature (RT) and $850^{\circ} \mathrm{C}$ was analyzed by differential scanning calorimetry (DSC) and thermal gravimetry (TG) using a 
Netzsch STA 449 apparatus. For these analyses, a $100 \mathrm{mg}$ sample was heated under a continuous gas stream $\left(20 \mathrm{~mL} / \mathrm{min}\right.$ of $\mathrm{N}_{2}$ protective gas and $50 \mathrm{~mL} / \mathrm{min}$ of air as purging gas) at a rate of $10 \% \mathrm{~min}$.

The thermal conversion of samples $\mathrm{Cu} \_0$ and $\mathrm{Cu} \_150$ was studied by stepwise heating from 200 to $1000^{\circ} \mathrm{C}$ in steps of $100^{\circ} \mathrm{C}$, measuring for $1 \mathrm{~h}$ at each step. A more detailed investigation was performed between 600 and $700^{\circ} \mathrm{C}$ where the samples were heated in steps of $25^{\circ}$, again measuring for $1 \mathrm{~h}$ at each step. Heating, cooling, and storage of the samples were under ambient atmosphere conditions.

The structural properties of the samples were determined by X-ray diffraction (XRD, Siemens D5000, with $\mathrm{CuK} \alpha$ radiation). The samples were hand ground in ethanol and pipetted onto a silicon singlecrystal plate. The XRD patterns were obtained in stepscan mode from 2 to $65^{\circ} 2 \theta$ with a step width of $0.03^{\circ} 2 \theta$ and $8 \mathrm{~s}$ per step. Single-line fitting was performed using the Bruker Topas V2.1 software package. The crystallite size of the samples was evaluated by the full width at half maximum (FWHM) of the 001 and the 060, 330 peaks according to the Scherrer equation, following the method described by Klug and Alexander (1975).

Fourier-transform infrared (FTIR) and EPR spectroscopy were conducted on the starting material, the hydrothermally-treated, and the stepwise-heated samples. The FTIR transmission spectra were obtained using either a Bruker IFS 66/S or a Perkin Elmer 2000 device using pellets prepared by mixing $\sim 2 \mathrm{mg}$ sample with $200 \mathrm{mg}$ of $\mathrm{KBr}$. The local structural environments of $\mathrm{Cu}(\mathrm{II})$ and $\mathrm{Fe}(\mathrm{III})$ were investigated by EPR spectroscopy; the principles of this method were given by Wertz and Bolton (1972). The X-band (9.8 GHz) EPR spectra were recorded at room temperature on a Bruker EMX spectrometer, at $6 \mathrm{~mW}$, a modulation amplitude of $0.1 \mathrm{mT}$, and a modulation frequency of $100 \mathrm{kHz}$. A Hall probe was used to measure the field strength. Lowtemperature measurements at $-257^{\circ} \mathrm{C}$ were carried out using a Bruker ELEXSYS E500 at $9.48 \mathrm{GHz}$, a power of $0.2 \mathrm{~mW}$, and modulation amplitude of $1 \mathrm{mT}$. In addition, Q-band $(33.418 \mathrm{GHz})$ measurements at room temperature were performed on the sample heated to $1000^{\circ} \mathrm{C}$ using a Bruker ELEXSYS E580. By employing higher frequency, better resolution is obtained for samples with anisotropic g-values or for samples in which different paramagnetic species with different g-values coexist. The simulation of the spectra was carried out using the EasySpin routine, a Matlab code developed in the EPR group at ETH Zürich (Stoll and Schweiger, 2006).

The EPR spectroscopy was completed by measuring samples $\mathrm{Cu} 150$ and $\mathrm{Cu} 500$ after EDTA treatment. For this treatment, 2-4 $\mathrm{g}$ of sample was suspended in $400 \mathrm{~mL}$ of $0.2 \mathrm{M} \mathrm{Na}_{4}$-EDTA ( $\mathrm{pH} \mathrm{11)} \mathrm{and} \mathrm{mixed} \mathrm{using}$ an end-over-end shaker for $24 \mathrm{~h}$. After mixing, the suspension was centrifuged and the supernatant discarded. The whole procedure was repeated. Afterwards, the sample was washed in ethanol until the $\mathrm{pH}$ in the supernatant was stable. All treated samples were dried at $65^{\circ} \mathrm{C}$. In order to estimate the $\mathrm{Cu}(\mathrm{II})$ content removed by EDTA, EPR spectra of equal amounts of $\mathrm{Cu}_{-} 0$ and of $\mathrm{Cu} 500$ before and after EDTA treatment were recorded at RT. The removal by EDTA was determined as the intensity difference between the $\mathrm{Cu}_{-} 0$-corrected spectra of the EDTA-treated and untreated $\mathrm{Cu}_{-} 500$ sample determined by double integration.

For transmission electron microscopy (TEM; Philips CM200 operated at $200 \mathrm{kV}$ ), the sample $\mathrm{Cu} 150$, after heating to $650^{\circ} \mathrm{C}$, was selected. The powder was suspended in acetone and deposited on carbon-coated copper grids. Selected-area electron diffraction (SAED) patterns were indexed using the EMS software package (Stadelmann, 1987).

\section{RESULTS}

\section{Hydrothermal treatment}

The XRD pattern of the starting material shows the characteristic peaks of hectorite (Figure 1). Hydrothermal treatment led to a narrowing of the peaks. The narrowing was best observed for the 001 and 060,330 peaks. The crystallite sizes deduced from the FWHM of these two Bragg peaks and expressed as mean coherence length $(\mathrm{mcl})$ increased upon hydrothermal treatment (Figure 1, inset). This increase was more pronounced for 060,330 . The presence of $\mathrm{Cu}$ (II) in

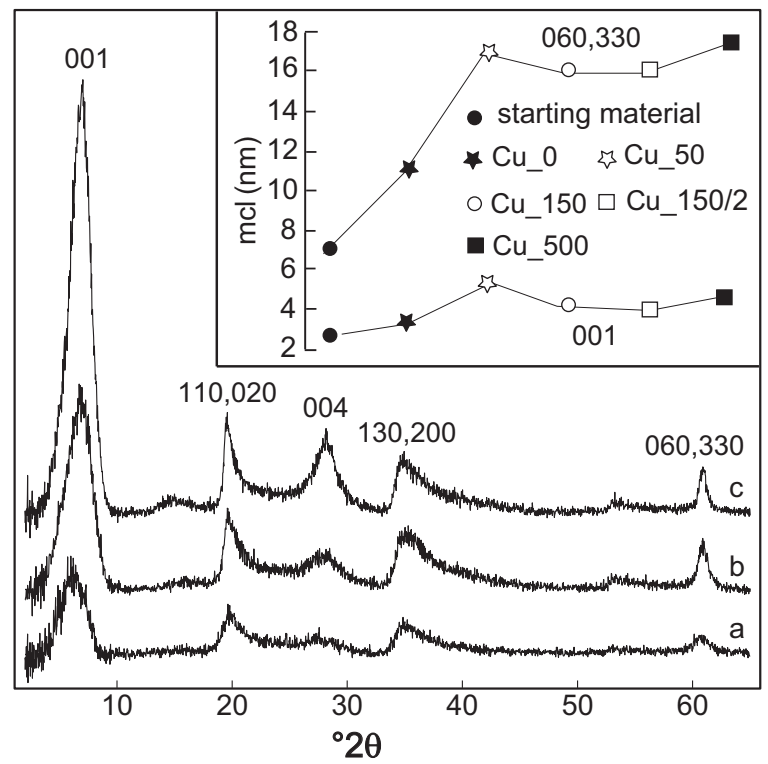

Figure 1. XRD patterns of the starting material (a), and the hydrothermally treated samples $\mathrm{Cu} 0$ (b) and $\mathrm{Cu} 150$ (c) after removing the background signal; the major peaks are indicated. The inset shows the average mean coherence length $(\mathrm{mcl})$ of the crystallites deduced from FWHM of (001), and $(060) /(330)$ reflections for the samples $(\mathrm{a}-\mathrm{c})$ and the samples $\mathrm{Cu}_{-} 50$, $\mathrm{Cu} \_150 / 2$ (replicate) and $\mathrm{Cu} 500$. 
the hydrothermal solution enhanced this effect (Figure 1).

The FTIR spectra of the starting material revealed, in the mid-infrared region, a band at $3680 \mathrm{~cm}^{-1}$ typical of $\mathrm{O}-\mathrm{H}$-stretching vibrations in hectorite (data not shown).

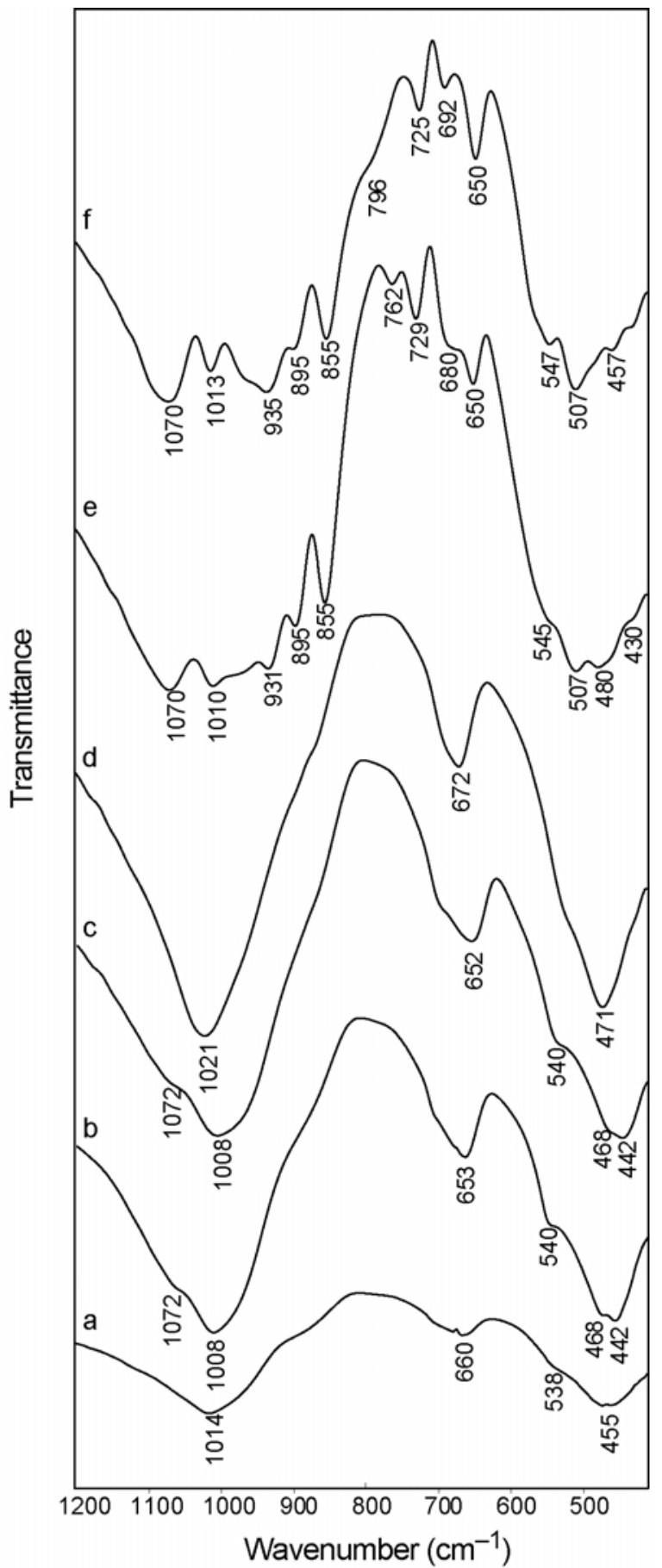

Figure 2. Room-temperature, mid-FTIR spectra of the starting material (a), and the hydrothermally treated samples $\mathrm{Cu} 0$ (b), $\mathrm{Cu} \_150(\mathrm{c})$, and $\mathrm{Cu} \_150$ stepwise heated at $600^{\circ} \mathrm{C}(\mathrm{d}), 650^{\circ} \mathrm{C}(\mathrm{e})$, and $1000^{\circ} \mathrm{C}$ (f).
According to Farmer (1974), the broad bands at 1014 and $455 \mathrm{~cm}^{-1}$ can be attributed to $\mathrm{Si}-\mathrm{O}$ stretching, the bands at $660 \mathrm{~cm}^{-1}$ and the weak shoulder at $538 \mathrm{~cm}^{-1}$ to $\mathrm{O}-\mathrm{H}$ bending and to $\mathrm{Mg}-\mathrm{O}$ vibrations, respectively (Figure 2). After hydrothermal treatment, the bands became sharper and an additional shoulder occurred at $1072 \mathrm{~cm}^{-1}$ (Figure 2). The addition of $\mathrm{Cu}(\mathrm{II}) \mathrm{did}$ not lead to significant changes in the positions of the bands.

Wide-range EPR spectra of the starting material revealed a broad feature centered at $\mathrm{g} \approx 2$ and $\mathrm{a}$ resonance at $\mathrm{g}=4.3$ (Figure $3 \mathrm{a}$ ). These features could be attributed to traces of ferric oxides/hydroxides, and to $\mathrm{Fe}(\mathrm{III})$ in octahedral sites with rhombic distortion, respectively (e.g. Meads and Malden, 1975; Gehring and Hofmeister, 1994). No significant spectral changes were observed upon hydrothermal treatment (Figure 3b). Adding $\mathrm{Cu}(\mathrm{II})$ nitrate or chloride to the hydrothermal solution led to an additional hyperfine split signal (Figure 3c). The four features are typical for parallel components of $\mathrm{Cu}(\mathrm{II})$ with a nuclear spin of $3 / 2$ (e.g. Wertz and Bolton, 1972). The perpendicular component consisted of a doublet with perpendicular $g$ values $\left(g_{\perp}\right)$ of 2.05 and 2.04. The relative intensity of the two peaks varied with $\mathrm{Cu}(\mathrm{II})$ concentration (Figure 4). Lowtemperature measurements at $-257^{\circ} \mathrm{C}$ led to greater resolution of the parallel component whereas the perpendicular component revealed only one feature with $g_{\perp}=2.05$ (Figure 5). Spectral parameters for two parallel components with different $\mathrm{g}_{\|}$values of 2.42 and 2.32 and $\mathrm{A}$ values of 10.0 and $9.2 \mathrm{mT}$, respectively,

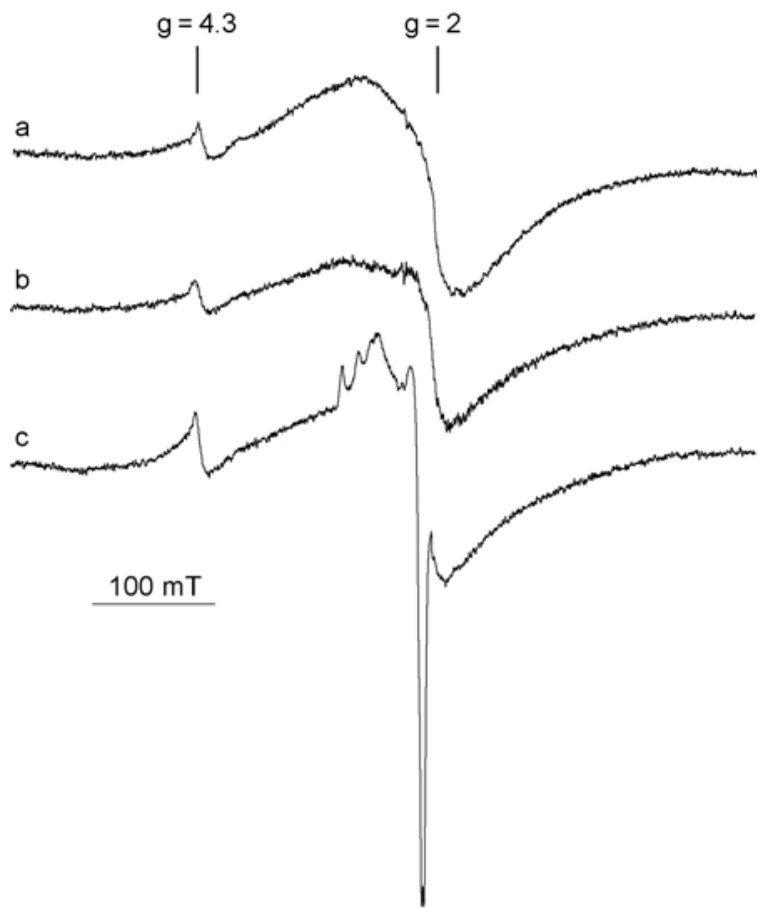

Figure 3. Wide-range EPR spectra of the starting material (a), and the hydrothermally treated samples $\mathrm{Cu}_{-} 0$ (b) and $\mathrm{Cu}_{-} 150$ (c). 


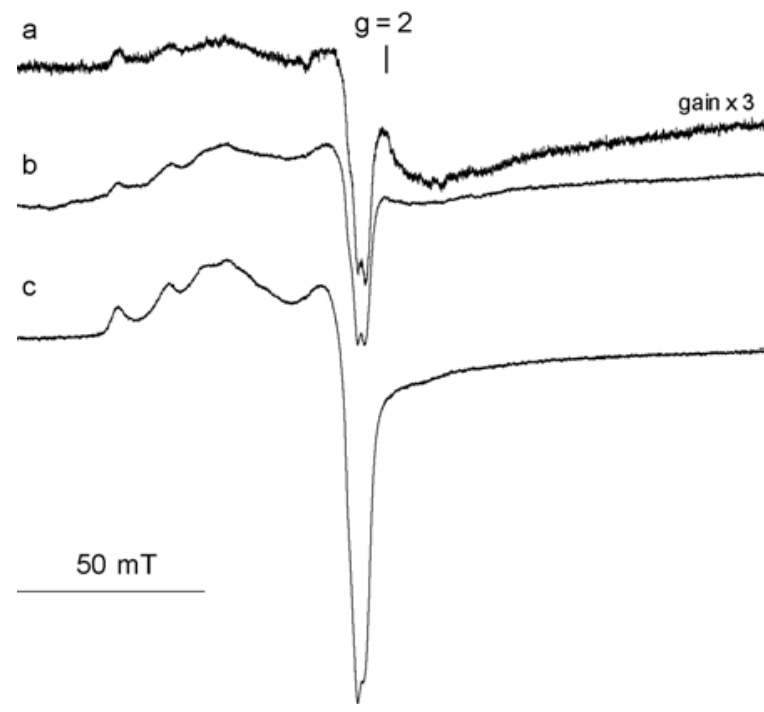

Figure 4. Narrow-range EPR spectra of the hydrothermally treated samples $\mathrm{Cu} \_50(\mathrm{a}), \mathrm{Cu} \_150(\mathrm{~b})$, and $\mathrm{Cu} \_500$ (c).

could be deduced from the low-temperature spectra. Treatment with EDTA led to a decrease in the $\mathrm{Cu}(\mathrm{II})$ signal intensity (Figure 5). The remaining signal revealed no significant spectral changes. The amount of $\mathrm{Cu}$ (II) removed by EDTA was $20 \%$. A similar value was found by Luca et al. (1991) for co-precipitated fluoro-hectorite.

\section{Thermal treatment}

The DSC curve of the starting material revealed a first endothermic peak at $149^{\circ} \mathrm{C}$ associated with a weight loss of $17 \%$. A second, weak endothermic peak was found at $734^{\circ} \mathrm{C}$ followed by a sharp exothermic peak at $748^{\circ} \mathrm{C}$. The latter occurred simultaneously with the step in the TG curve between 747 and $753^{\circ} \mathrm{C}$ (Figure 6a).

All hydrothermally treated samples exhibited an endothermic peak at $\sim 145^{\circ} \mathrm{C}$. The $\mathrm{Cu}$-free sample showed two additional endothermic peaks, a broader one at $714^{\circ} \mathrm{C}$ and a sharper one at $739^{\circ} \mathrm{C}$ (Figure 6b). The first peak occurred before whereas the second one was within the step in the TG curves between 722 and $744^{\circ} \mathrm{C}$. The DSC curve of the Cu-treated samples decreased steadily between 300 and $600^{\circ} \mathrm{C}$. At greater temperatures, a pronounced endothermic feature with a peak at $702^{\circ} \mathrm{C}$ was found (Figure $6 \mathrm{c}$ ). This endothermic feature occurred concomitantly with a major weight loss between 690 and $725^{\circ} \mathrm{C}$

$\mathrm{X}$-ray diffraction of the products after DSC analysis revealed enstatite $\left(\mathrm{MgSiO}_{3}\right)$ in all samples (Figure 7). In addition, Mg-F richterite $\left(\mathrm{Na}_{2} \mathrm{Mg}_{6} \mathrm{Si}_{8} \mathrm{O}_{22} \mathrm{~F}_{2}\right.$ ) (Gibbs et al., 1962) and a distinct diffraction peak of cristobalite $\left(\mathrm{SiO}_{2}\right)$ were detected for the $\mathrm{Cu}$-treated samples.

The XRD analysis of the conversion via stepwise heating of the sample $\mathrm{Cu} 150$ revealed an intact hectorite with $d_{001}$ spacing of $9.77 \AA$ at $600^{\circ} \mathrm{C}$ (Figure 8a). Additional peaks occurred after heating to

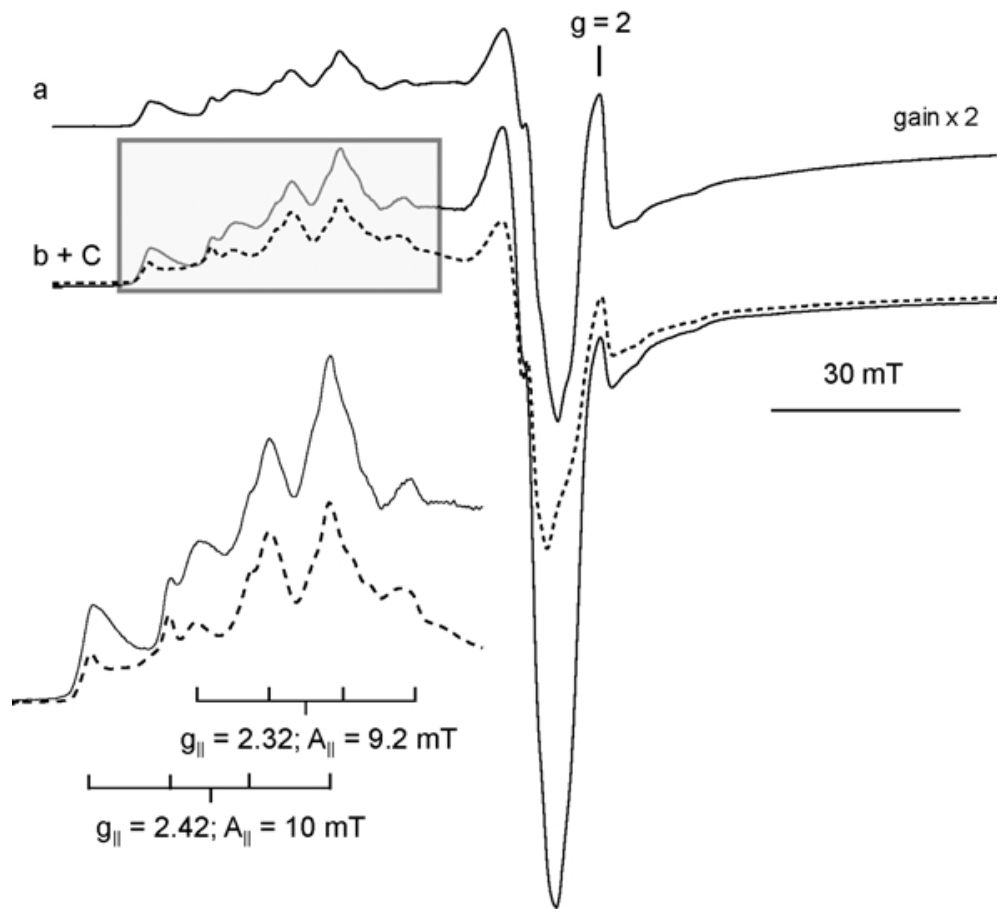

Figure 5. Low-temperature EPR spectrum at $-257^{\circ} \mathrm{C}$ of the hydrothermally treated sample Cu_150 (a), Cu_500 (b, solid line), and Cu_500 after EDTA treatment (c, dashed line). The inset shows an enlarged view of the parallel component. 
$625^{\circ} \mathrm{C}$, which could be assigned to the 310,110 , and 040 reflections of F-rich Mg-richterite (Gibbs et al., 1962) and to major reflections of enstatite. After heating to $650^{\circ} \mathrm{C}$, the hectorite peaks vanished and at $700^{\circ} \mathrm{C}$ cristobalite was detected. At $1000^{\circ} \mathrm{C}$, richterite disappeared and the peaks of enstatite and cristobalite became sharper, and additional peaks attributed to proto-enstatite
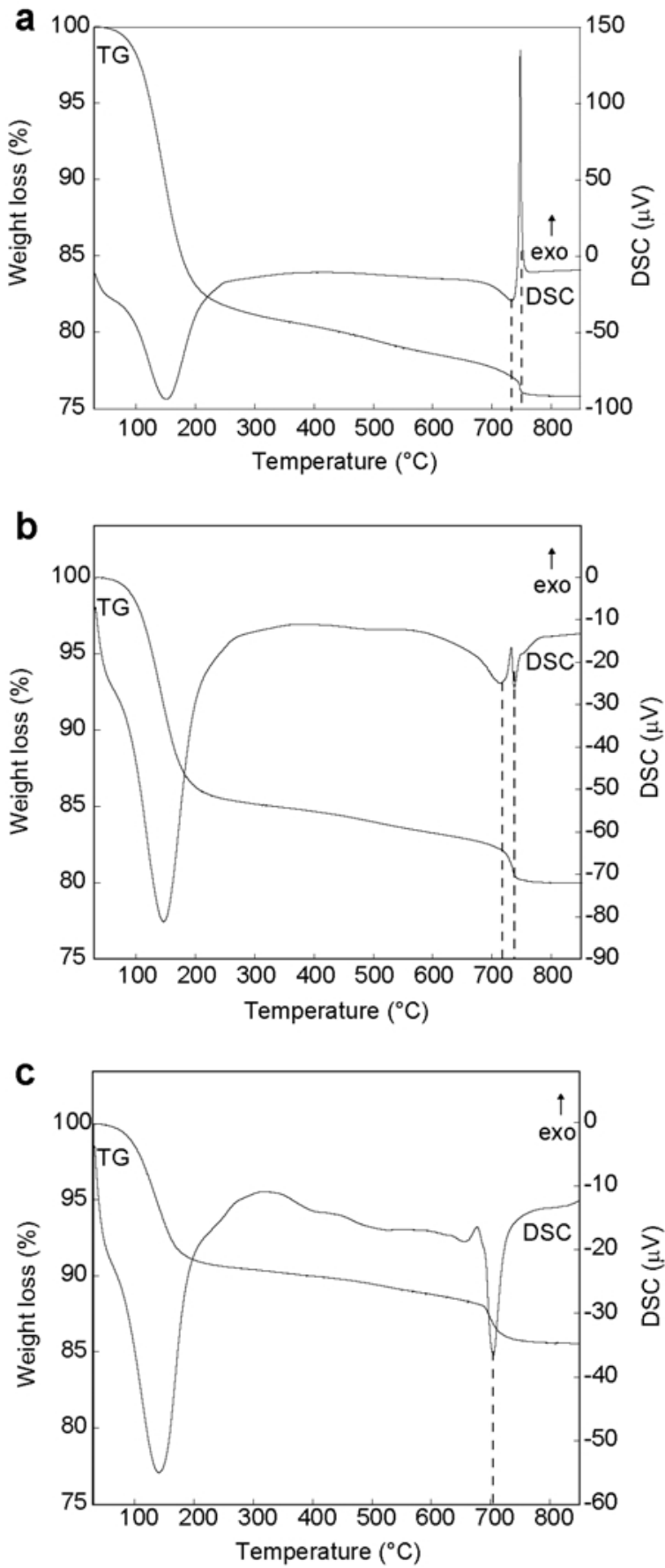

Figure 6. DSC and TG curves of the starting material (a), and the hydrothermally treated samples $\mathrm{Cu} 0$ (b) and $\mathrm{Cu} \_150$ (c). occurred. Step-wise heating of $\mathrm{Cu} \_0$ showed no richterite and the breakdown of the hectorite structure occurred at higher temperature between 650 and $675^{\circ} \mathrm{C}$ (Figure $8 \mathrm{~b}$ ). The formation of richterite in the presence of $\mathrm{Cu}(\mathrm{II})$ was confirmed by TEM analysis of sample $\mathrm{Cu} \_150$ heated at $650^{\circ} \mathrm{C}$. This phase exhibited a needlelike morphology and its selected area electron diffraction patterns could be indexed for a monoclinic amphibole $C 2 / m$ (Figure 9).

The FTIR spectrum of the $\mathrm{Cu} 150$ heated at $600^{\circ} \mathrm{C}$ exhibited poorer resolution than the RT spectrum and only the major bands were visible (Figure 2d). After heating at $650^{\circ} \mathrm{C}$, the band at $3680 \mathrm{~cm}^{-1}$ vanished, indicating the loss of hydroxyl groups. Furthermore, in the range characteristic of $\mathrm{Si}-\mathrm{O}$ stretching (1100-800 $\mathrm{cm}^{-1}$ ), several bands were generated due to the formation of enstatite and richterite. Considering these two phases, the bands at $762,729,680$, and $650 \mathrm{~cm}^{-1}$ could be assigned to vibrations of tetrahedral chains whereas the bands at smaller wavenumbers $(545,507$, $430 \mathrm{~cm}^{-1}$ ) could arise from lattice modes (e.g. Tarantino et al., 2002) or from $\mathrm{Mg}-\mathrm{O}$ vibrations $\left(480 \mathrm{~cm}^{-1}\right)$ (Strens, 1974 ). At $1000^{\circ} \mathrm{C}$, the FTIR spectrum became better resolved and all bands were attributed to enstatite (Bilton et al., 1972). The distinct shoulder at $796 \mathrm{~cm}^{-1}$ is indicative of cristobalite (Gadsen, 1975). Compared to the spectrum at $650^{\circ} \mathrm{C}$, the band at $762 \mathrm{~cm}^{-1}$ was missing in the sample heated at $1000^{\circ} \mathrm{C}$.

Room-temperature EPR spectroscopy of sample $\mathrm{Cu} \_150$ heated at $400^{\circ} \mathrm{C}$ showed the generation of a

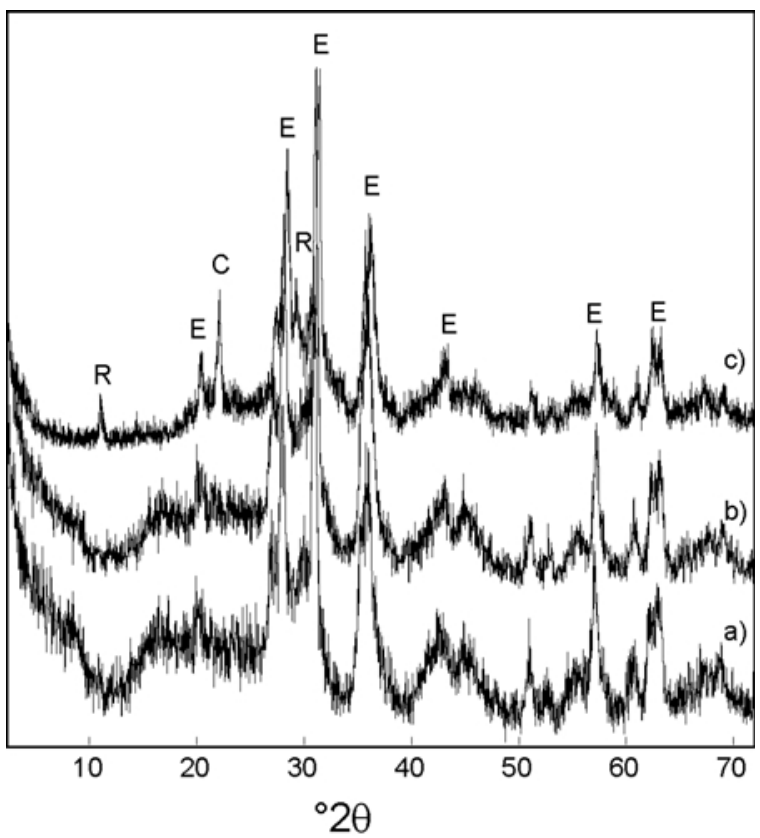

Figure 7. XRD patterns of the starting material (a), and the hydrothermally treated samples $\mathrm{Cu} 0$ (b) and $\mathrm{Cu} 150$ (c) after calorimetric analysis; $\mathrm{E}=$ enstatite, $\mathrm{C}=$ cristobalite, $\mathrm{R}=$ richterite. 
sharp signal at $\mathrm{g}=2$. This signal reached a maximum for the sample annealed at $600^{\circ} \mathrm{C}$ and vanished above $700^{\circ} \mathrm{C}$ (Figure 10). Such a signal can be assigned to free radicals (e.g. Wertz and Bolton, 1972). The formation of radicals was also observed for $\mathrm{Cu}$-free samples. The $\mathrm{Fe}$ (III) signal at $\mathrm{g}=4.3$ remained stable for treatments up to $600^{\circ} \mathrm{C}$. For samples annealed at higher temperatures, new absorption features in the g-value range of 3.3 to 9 were generated (Figure 11). The better-resolved signals indicated distinct $\mathrm{Fe}(\mathrm{III})$ sites in the conversion products with different rhombic distortions (Jones et al., 1974). The $\mathrm{Cu}(\mathrm{II})$ signal showed only little changes for samples heated up to $600^{\circ} \mathrm{C}$ (Figure 4 and 10) but a new signal with a strong feature at $\mathrm{g}=2.36$ and weaker components at $\mathrm{g}<2$ appeared for the sample annealed at $625^{\circ} \mathrm{C}$ (Figure 10 ). The signal at $\mathrm{g}=2.36$ increased at the expense of the signal at $\mathrm{g}=2.05$ for annealing temperatures between $625^{\circ}$ and $650^{\circ} \mathrm{C}$. No further increase was observed for the higher annealing temperatures. At $1000^{\circ} \mathrm{C}$ the signal was better resolved. The Q-band EPR spectrum of sample $\mathrm{Cu} 150$ heated to $1000^{\circ} \mathrm{C}$ exhibited two signals, characteristic for $\mathrm{Cu}(\mathrm{II})$ in sites with rhombic and axial distortions, respectively

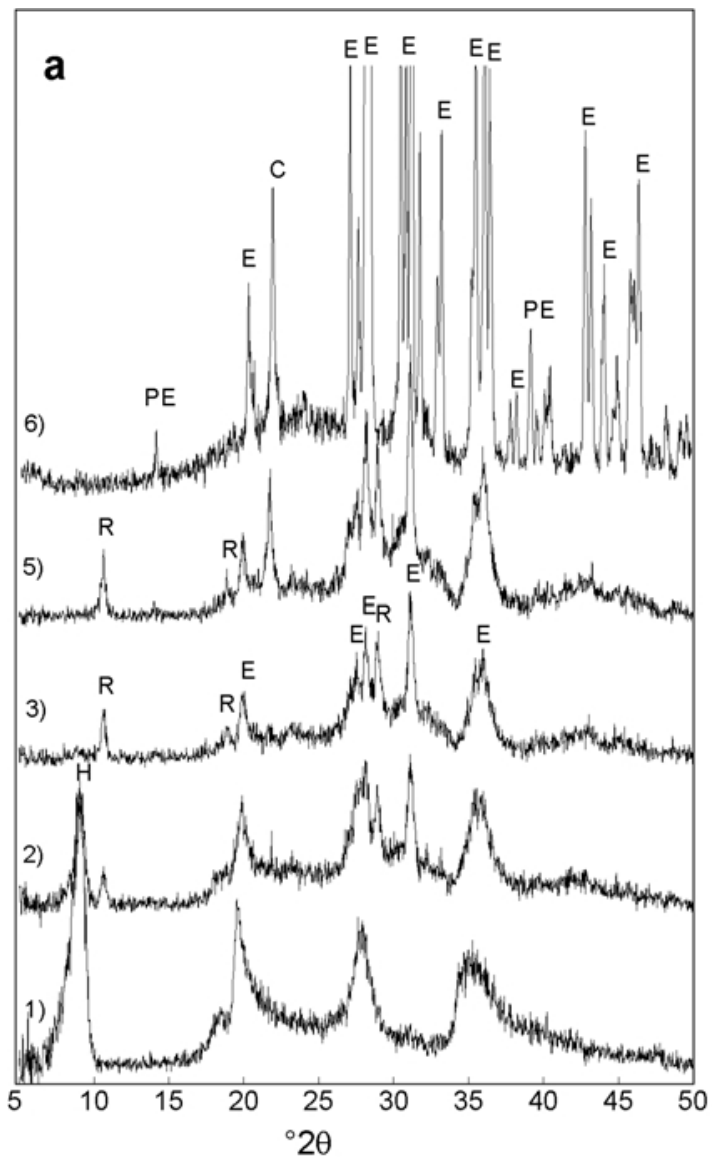

(Figure 12). The spectral parameters for the rhombic site were $g_{\mathrm{xx}}=2.33, \mathrm{~g}_{\mathrm{yy}}=2.29, \mathrm{~g}_{\mathrm{zz}}=1.99, \mathrm{~A}_{\mathrm{zz}}=15 \mathrm{mT}$, and $\mathrm{A}_{\mathrm{xx}}=7 \mathrm{mT}$; no splitting was found for the y component. For the axial site, $g_{\perp}=2.05$ was measured, while the parallel component was unresolved. The best simulation of the spectrum was obtained with $\mathrm{g}_{\|}=2.400$ and $\mathrm{g}_{\perp}=$ 2.055 for the axial sites (Figure 12). A ratio of 8 between $\mathrm{Cu}(\mathrm{II})$ in rhombic and axially distorted sites was also estimated from the spectral simulation.

\section{DISCUSSION}

\section{$\mathrm{Cu}$ in the modified starting material}

The XRD and FTIR data of Kloprogge et al. (1998) clearly show that the crystallinity, i.e. the size of the crystallite, increases preferentially within the basal plane of the hectorite during hydrothermal treatment. The less pronounced narrowing of the basal reflections in the XRD patterns may also be due to the presence of stacking faults, which limit the coherence length. Since no $\mathrm{Mg}$ or $\mathrm{Si}$ was added to the solutions, the increase in crystallite size can be explained by coalescence, or by dissolution-precipitation (recrystallization). The fact that

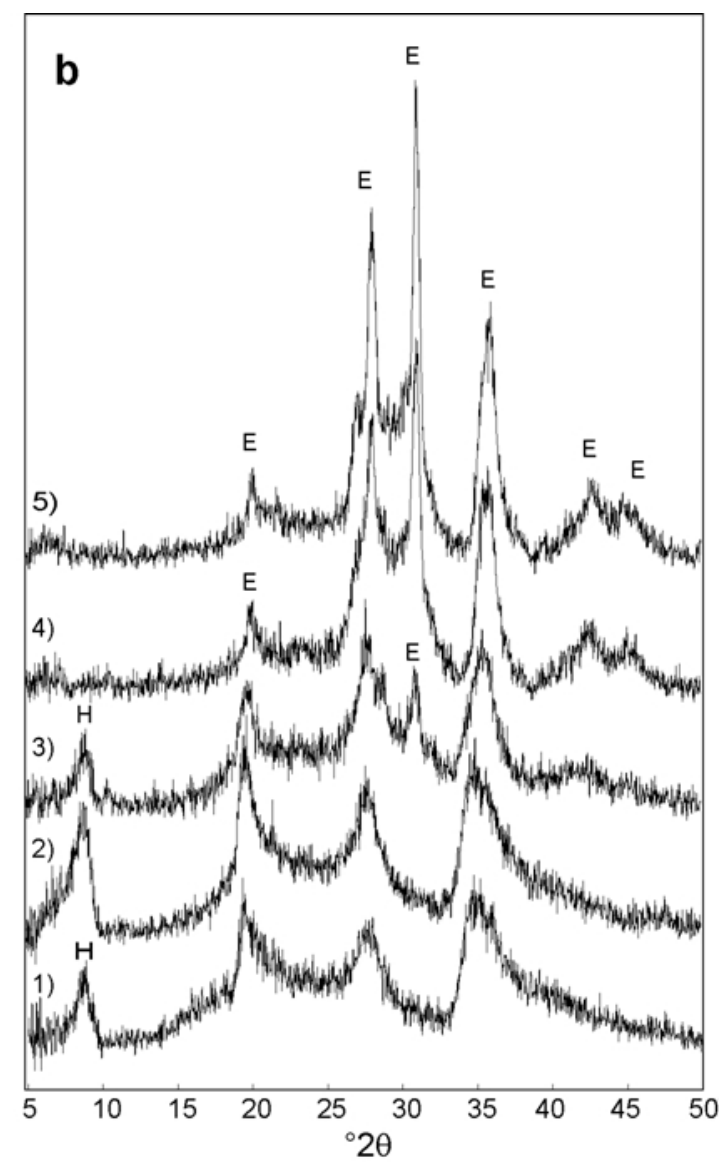

Figure 8. XRD patterns of the hydrothermally treated sample $\mathrm{Cu} 150$ (a) and $\mathrm{Cu} \_0$ (b) after stepwise heating at $600^{\circ} \mathrm{C}(1), 625^{\circ} \mathrm{C}(2)$, $650^{\circ} \mathrm{C}(3), 675^{\circ} \mathrm{C}(4), 700^{\circ} \mathrm{C}(5)$, and $1000^{\circ} \mathrm{C}(6) . \mathrm{H}=$ hectorite $\overline{\mathrm{E}}=$ enstatite, $\mathrm{PE}=$ protoenstatite, $\mathrm{C}=$ cristobalite, $\mathrm{R}=$ richterite. 
$\mathrm{Cu}$ (II) enhanced the crystallinity suggests that the metal cation is substituted into the hectorite structure rather than forming a separate phase. This interpretation is supported by the hyperfine splitting of the EPR signals which indicates isolated $\mathrm{Cu}(\mathrm{II})$ binding sites associated with hectorite. The well resolved signal can be assigned to $\mathrm{Cu}$ (II) in axially distorted sites. Such sites can occur in the structure or at the inner surface, i.e. interlayers and hexagonal cavities of the hectorite (Clementz et al., 1973; Luca et al., 1991; Karakassides et al., 1999; Spagnuolo et al., 2004). The spectral parameters $\mathrm{g}_{\|}=$ 2.42 and $\mathrm{A}_{\|}=10 \mathrm{mT}$, obtained from low-temperature measurements, are similar to the parameters determined by Luca et al. (1991) and assigned to structure-bound $\mathrm{Cu}(\mathrm{II})$. The other spectral parameters found for our
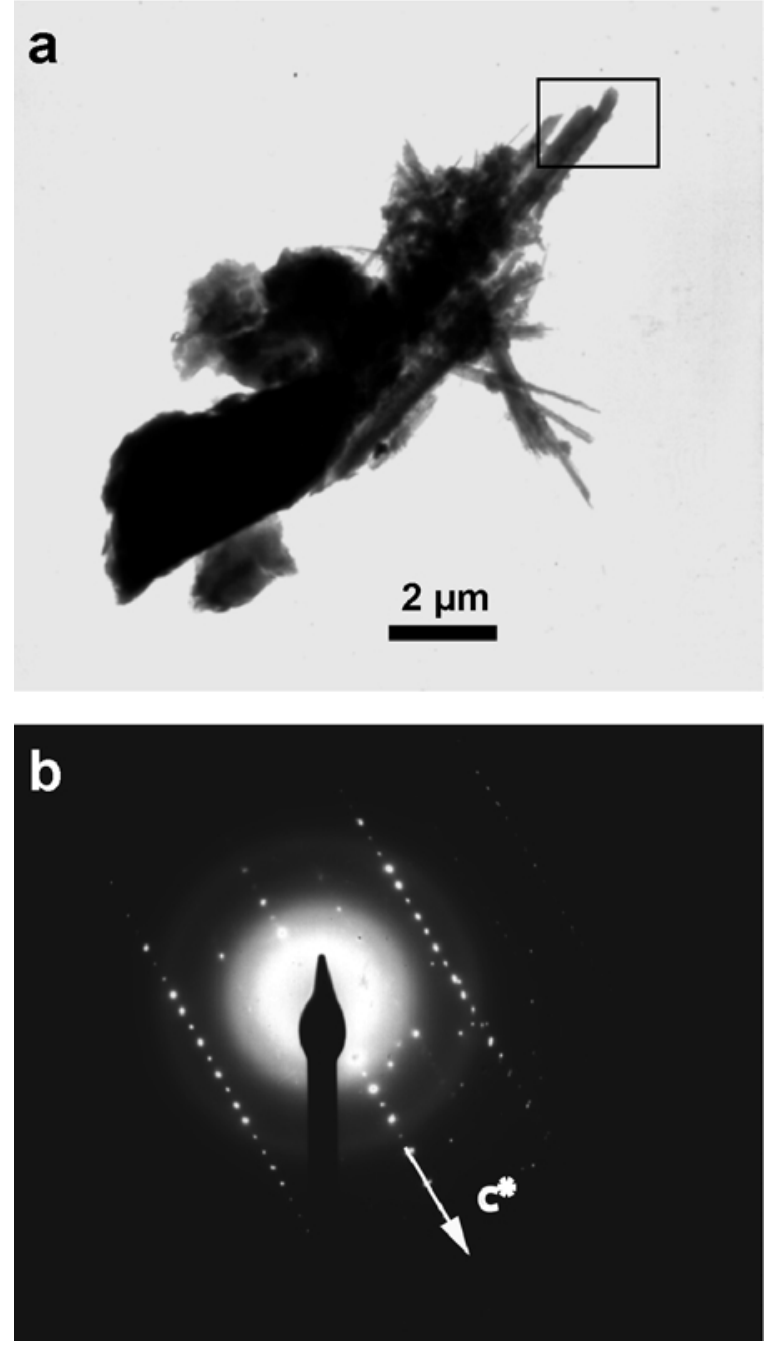

Figure 9. Bright-field image of the hydrothermally treated sample $\mathrm{Cu} 150$ heated at $650^{\circ} \mathrm{C}$ showing the needle-shaped amphibole (a); part (b) shows the (-202) SAED pattern for monoclinic amphibole in the area marked in (a). The pattern was taken with the aperture placed over the two lath-like crystals on top of the aggregate. sample $\left(\mathrm{g}_{\|}=2.32, \mathrm{~A}_{\|}=9.2 \mathrm{mT}\right)$ are different from $\mathrm{Cu}(\mathrm{II})$ sites in hectorite deduced by Luca et al. (1991) and from $\mathrm{Cu}(\mathrm{II})$ in interlayers (Clementz et al., 1973). Therefore, an unambiguous assignment of this signal to a specific site cannot be made. The fact that both sites respond in similar fashion to EDTA treatment indicates, however, that this $\mathrm{Cu}(\mathrm{II})$ is also closely associated with the structure, possibly coordinated with siloxane cavities. Copper(II) bound in octahedral sheets is generally protected from EDTA attack except for locations exposed at edges. Similarly, for steric reasons, $\mathrm{Cu}(\mathrm{II})$ bound in siloxane cavities can be expected not to be removed easily by EDTA.

The doublet near $\mathrm{g}=2$ recorded at RT (Figure 4) can also be explained by the two $\mathrm{Cu}$ (II) sites. Changes in the relative intensity of the two signals with increasing $\mathrm{Cu}$ (II) concentration can be interpreted as changes in the relative occupation of the different $\mathrm{Cu}$ (II) sites.

\section{Thermal conversion}

The thermal analysis demonstrates that $\mathrm{Cu}(\mathrm{II})$ affects the calorimetric behavior of hectorite and its conversion

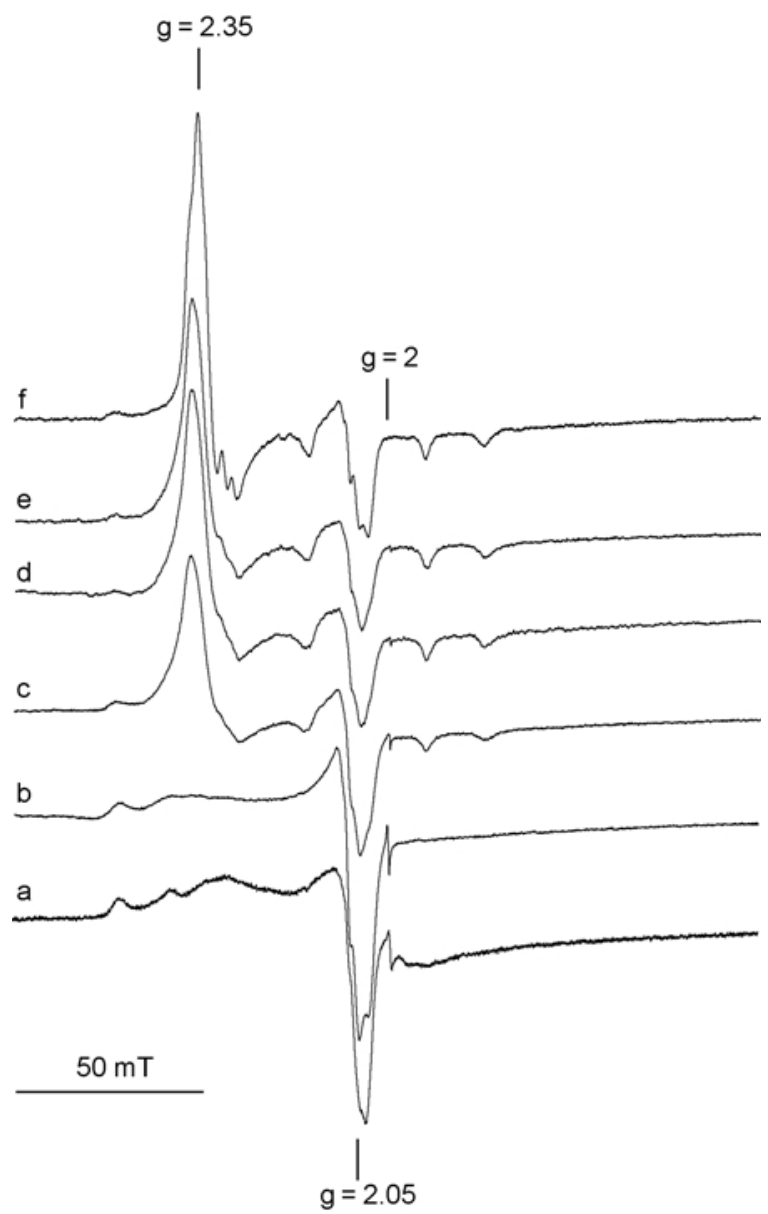

Figure 10. EPR spectra of the hydrothermally treated sample $\mathrm{Cu} 150$ after stepwise heating at $400^{\circ} \mathrm{C}$ (a), $600^{\circ} \mathrm{C}$ (b), $625^{\circ} \mathrm{C}(\mathrm{c}), 650^{\circ} \mathrm{C}(\mathrm{d}), 700^{\circ} \mathrm{C}(\mathrm{e})$, and $1000^{\circ} \mathrm{C}$ (f). 


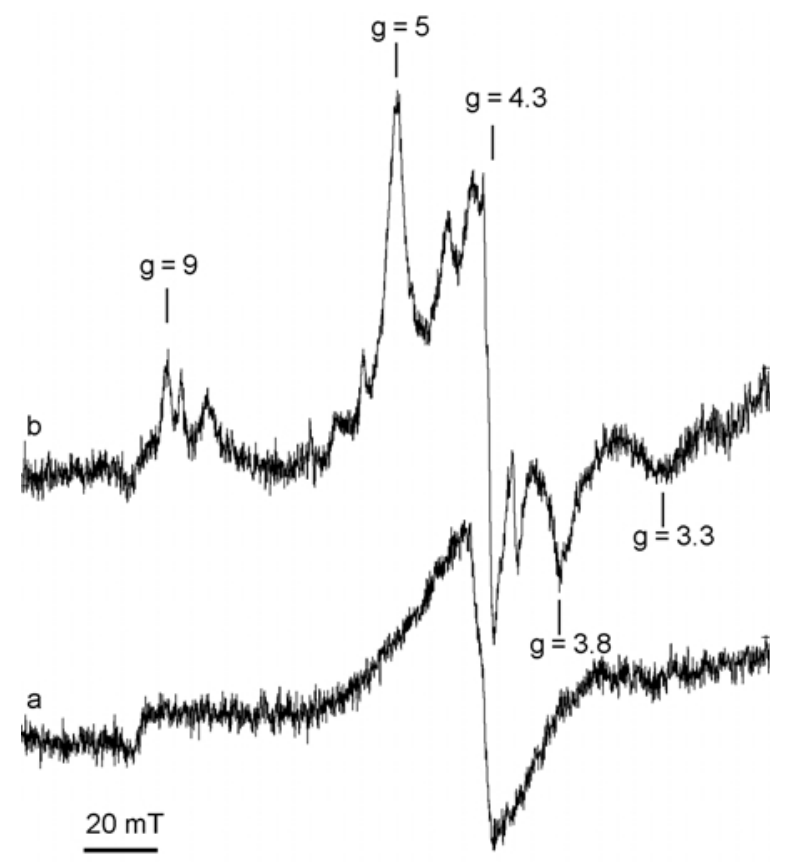

Figure 11. Low-field EPR spectra of the hydrothermally treated sample Cu_150 heated at $600^{\circ} \mathrm{C}$ (a) and $1000^{\circ} \mathrm{C}$ (b)

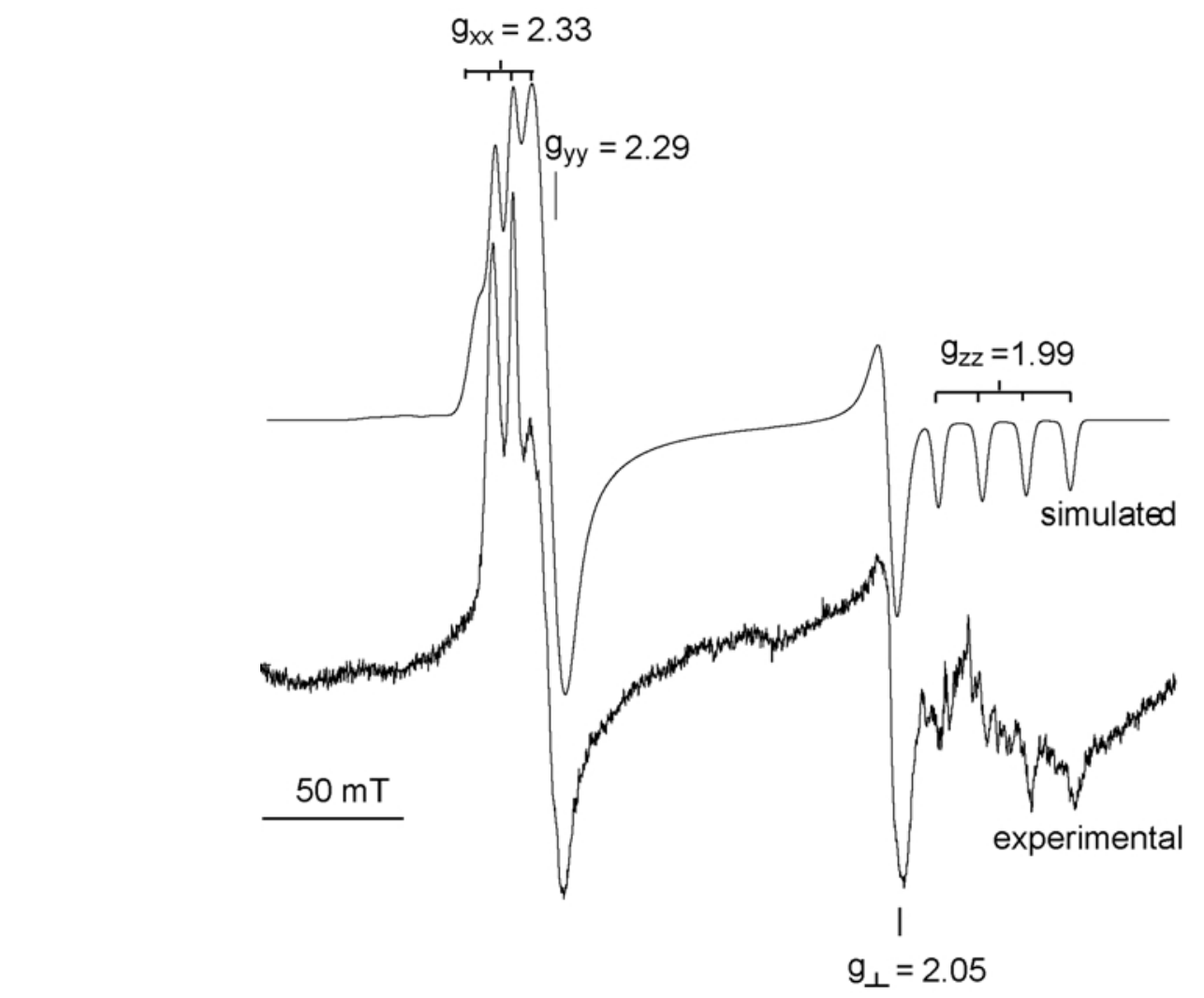

Figure 12. Experimental (a) and simulated (b) Q-band EPR spectra of hydrothermally treated sample Cu_150 heated at $1000^{\circ} \mathrm{C}$. products. The difference in the thermal behavior of the samples with and without $\mathrm{Cu}(\mathrm{II})$ becomes visible above $600^{\circ} \mathrm{C}$. In this temperature range, the starting material is characterized by simultaneous dehydroxylation and conversion to enstatite. The sharp exothermic peak for the untreated starting material indicates that the conversion of hectorite goes along with an increase in crystallinity. The absence of such a dominant exothermic peak for the hydrothermally treated samples suggests that the hydrothermally treated samples are better crystallized, which agrees well with the XRD data.

For hectorite, Chipera and Bish (2002) showed that defluorination takes place at greater temperatures than dehydroxylation. With this in mind, the two endothermic features in the hydrothermally treated $\mathrm{Cu}(\mathrm{II})$-free sample can be interpreted as two-step structural break down, the first feature related to dehydroxylation and the second to defluorination of the thermally more stable fluorineenriched areas in the hectorite. The occurrence of only one endothermic feature at the smaller temperature for the $\mathrm{Cu}$ (II)-treated samples suggests no significant defluorination. Moreover, in such a case, the presence of $\mathrm{Cu}$ (II) triggers the formation of $\mathrm{Mg}-\mathrm{F}$ richterite. Since this phase can also be a conversion product of hectorite in the absence of $\mathrm{Cu}(\mathrm{II})$, but with a concentration of $\mathrm{F}$ which is five times greater than in the present experiment

8 
(Granquist and Pollack, 1959), Cu(II) probably influences either the distribution or the thermal stability of $\mathrm{F}$ in the sample. In the first case the simultaneous enrichment of $\mathrm{Cu}$ (II) and $\mathrm{F}$ would lead to broadening of the $\mathrm{Cu}$ (II) EPR signal due to dipole-dipole interactions, which was not observed. Furthermore, richterite formation is not affected by the $\mathrm{Cu} / \mathrm{F}$ ratio in the hydrothermal solution. All of this argues in favor of the second explanation, in which the conversion of hectorite occurs while still containing F. As a consequence, the conversion product contains a mineral phase such as $\mathrm{Mg}-\mathrm{F}$ richterite, which can stabilize F. Considering the mechanism of such a conversion, the substitution of $\mathrm{Cu}$ (II) for $\mathrm{Mg}$ (II) in the octahedral sheets of hectorite conceivably induces local instabilities due the Jahn-Teller effect. At these sites the breakdown of the octahedral sheets occurs preferentially and initiates the conversion. X-ray diffraction shows that richterite is only an intermediate product and, upon further heating to $1000^{\circ} \mathrm{C}$, converts to enstatite. At this temperature, both $\mathrm{Cu}$ (II) and $\mathrm{Fe}$ (III) occur in better crystallized structures as indicated by XRD and EPR spectroscopy. The conversion is illustrated schematically in Figure 13. In the absence of $\mathrm{Cu}(\mathrm{II})$, the randomized breaking apart of the hectorite structure occurs simultaneously with the dehydroxylation and release of $\mathrm{F}$. As a consequence, no amphibole can be formed. In the presence of $\mathrm{Cu}$ (II), the breaking apart of the hectorite structure begins at smaller temperature at sites with $\mathrm{Cu}$ (II) substitution. Fluorine-enriched areas of hectorite then adopt a stable amphibole structure, while the F-depleted areas convert directly to enstatite (Figure 13). Further increase in temperature converts the amphibole to an enstatite.
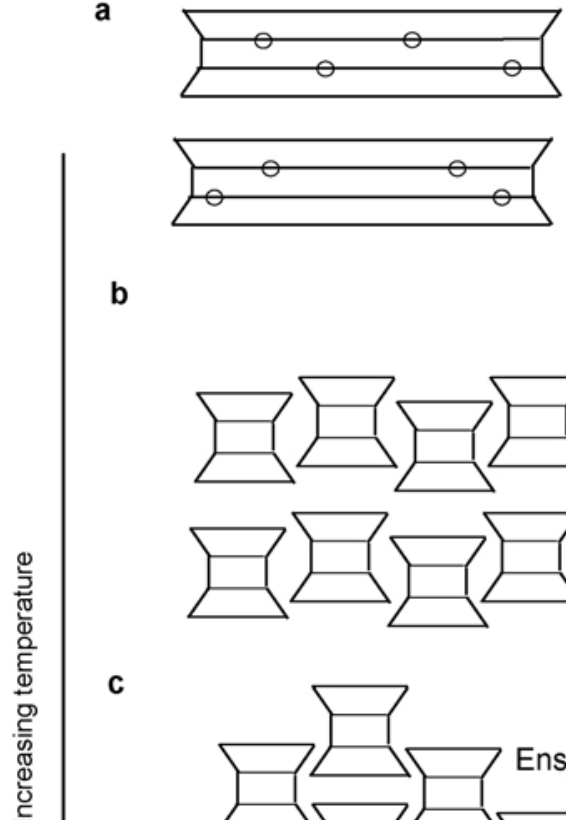

b
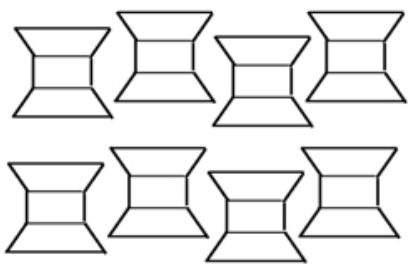

C

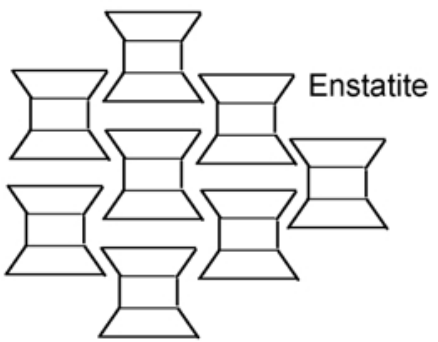

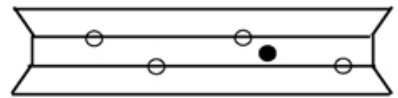
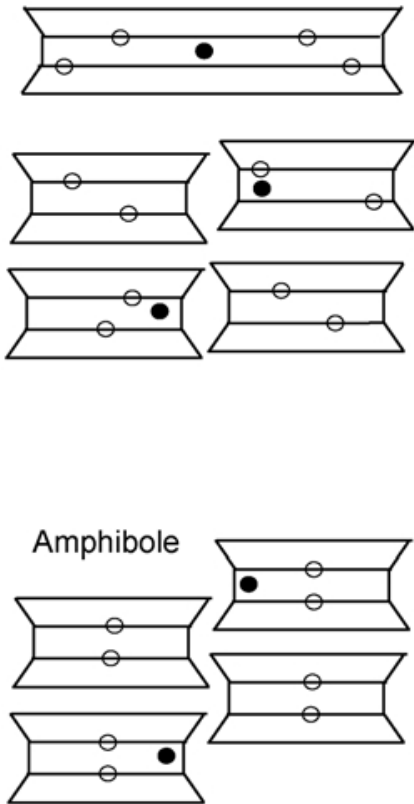

d

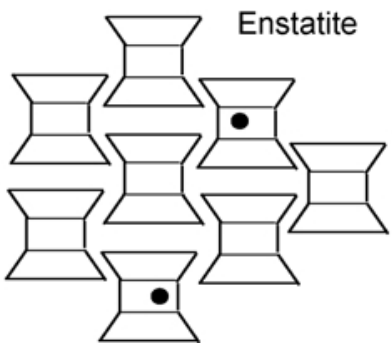

Figure 13. Schematic I-beam model of the thermal conversion of fluorine-enriched hectorite with (right) and without (left) structurebound $\mathrm{Cu}(\mathrm{II})$; open circles symbolize $\mathrm{F}^{-}$anions, and black circles octahedral sites with $\mathrm{Cu}(\mathrm{II})$ replacing $\mathrm{Mg}(\mathrm{II})$ or $\mathrm{Li}(\mathrm{I})$; (a) represents hectorite after hydrothermal treatment; (b) an intermediate conversion stage with partial hectorite destabilization; (c) the formation of enstatite and richterite, respectively, and (d) the breakdown of richterite. 
Spectroscopic evidence for the conversion of hectorite

On a molecular level, the first indication of a thermally induced destabilization of the hectorite structure is indicated by the appearance of a sharp EPR signal at $\mathrm{g}=2$ at $\sim 400^{\circ} \mathrm{C}$. Such a signal, which can be assigned to a free radical, has been observed in different natural and synthetic clay minerals (e.g. Meads and Malden, 1975; Gehring et al., 1993). Often, the radical disappears upon heating to $\sim 400^{\circ} \mathrm{C}$, i.e. structural defects heal. Schosseler and Gehring (1996) reported that, upon heating, such radicals were generated in vermiculite prior to its thermal breakdown. This was explained as the first sign of structural destabilization. The occurrence of thermally generated radicals in the present hectorite agrees well with the findings of Mandair et al. (1990). In their study on synthetic hectorite, they observed a change in the ${ }^{29} \mathrm{Si}$ NMR signal at $\sim 400^{\circ} \mathrm{C}$ and explained it by an increase in oxygen anions which are not bridging $\mathrm{SiO}_{4}$ tetrahedra. This structural change leads to dangling $\mathrm{Si}$ bonds ( $\mathrm{E}^{\prime}$ centers) and non-bridging oxygen hole centers which give rise to free radical signals (Mohanty et al., 2003). The maximum of the $\mathrm{g}=2$ signal in the $\mathrm{Cu} 150$ sample at $600^{\circ} \mathrm{C}$ points to the greatest concentration of defects close to the breakdown of the hectorite structure. At this temperature, interlayers are collapsed as indicated by $d_{001}<10 \AA$. These XRD and EPR data indicate that the conversion of hectorite starts at $600^{\circ} \mathrm{C}$. The similarity of the axial $\mathrm{Cu}$ (II) spectra yielded at this temperature and at RT proves that the $\mathrm{Cu}(\mathrm{II})$ coordination is only little affected by the early conversion stage. At $T>600^{\circ} \mathrm{C}$, where the hectorite structure breaks down, the spectra suggest that a minor amount of $\mathrm{Cu}$ (II) remains in nearregular octahedral sites whereas the majority of $\mathrm{Cu}(\mathrm{II})$ is forced into distorted sites with rhombic characteristics. These spectral changes suggest that $\mathrm{Cu}(\mathrm{II})$ is structure bound in richterite and/or enstatite.

The orthopyroxene structure has two sites: $M 1$ has rhombic characteristics, whereas $M 2$ is strongly distorted with six unequal $M-\mathrm{O}$ bond lengths. The Mg-amphiboles (e.g. antophyllite, cummingtonite, richterite) have at least one axially deformed octahedral site (Hawthorne and Oberti, 2007, Mineralogical Society of America Structure Database (http://www.minsocam.org/MSA/ Crystal_Database.html)). Among these amphiboles, richterite has a structure where three out of four octahedral sites have axial distortion. Such sites exhibit an ideal geometry for $\mathrm{Cu}(\mathrm{II})$ as the Jahn-Teller cation (Rao et al., 1992). This suggests that $\mathrm{Cu}(\mathrm{II})$ associated with hectorite can easily be transformed to axial sites of richterite. The fact that $\mathrm{Cu}$ (II) triggers the formation of $\mathrm{Mg}-\mathrm{F}$ richterite at a small fluoride content supports this assumption. However, this cannot be verified unambiguously by the EPR data, since enstatite also contains distorted octahedral sites which generate $\mathrm{Cu}(\mathrm{II})$ spectra (Mandair et al., 1990) similar to those found for the present samples. The stability of the $\mathrm{Cu}(\mathrm{II})$ signal at $1000^{\circ} \mathrm{C}$, where no richterite was found by XRD, proves $\mathrm{Cu}$ (II) in enstatite. This $\mathrm{Cu}$ (II) could be inherited from hectorite as well as from richterite which converts to pyroxene above $900^{\circ} \mathrm{C}$.

The electronic state of $\mathrm{Cu}$ (II) in the dominant rhombic sites of enstatite at $1000^{\circ} \mathrm{C}$ can be evaluated using the $\mathrm{R}$ factor proposed by Billing et al. (1971). This factor is defined as

$$
R=\frac{\left(g_{y y}-g_{z z}\right)}{\left(g_{x x}-g_{y y}\right)}
$$

for $g_{x x}>g_{y y}>g_{z z}$. The ground state for $R>1$ is predominantly $\mathrm{d}_{\mathrm{z}^{2}}$, whereas for $\mathrm{R}$ values $<1$ the characteristic ground state is $\mathrm{d}_{\mathrm{z}^{2}-\mathrm{y}^{2}}$. An $\mathrm{R}=7.5$ value for the rhombic sites in sample $\mathrm{Cu}_{-} 150$, treated at $1000^{\circ} \mathrm{C}$, thus indicates a $\mathrm{d}_{\mathrm{z}^{2}}$ ground state of $\mathrm{Cu}(\mathrm{II})$ in the enstatite. Such a configuration is unusual since $\mathrm{Cu}$ (II) in rhombic distorted sites generally has a $\mathrm{d}_{\mathrm{z}^{2}-\mathrm{y}^{2}}$ ground state (Poonguzhali et al., 2002). The $\mathrm{d}_{\mathrm{z}^{2}}$ ground state may have originated from local compression of rhombic sites in the enstatite structure.

\section{CONCLUSIONS}

(1) The presence of $\mathrm{Cu}(\mathrm{II})$ during the hydrothermal treatment of the synthetic hectorite increases the crystallite size.

(2) During hydrothermal treatment, a proportion of the $\mathrm{Cu}(\mathrm{II})$ is structure bound in octahedral sheets. The substitution of $\mathrm{Mg}(\mathrm{II})$ by $\mathrm{Cu}(\mathrm{II})$ creates domains of structural weakness which, upon heating, cause a reduction in the temperature of structural conversion. In the presence of $\mathrm{F}$, the thermally induced conversion leads to a Mg-F-richterite.

(3) The structural destabilization of hectorite begins at $\sim 400^{\circ} \mathrm{C}$, and the conversion to enstatite and/or richterite occurs between 600 and $650^{\circ} \mathrm{C}$. After this conversion, $\mathrm{Cu}(\mathrm{II})$ can be structure bound both in richterite or enstatite. At $1000^{\circ} \mathrm{C}$, after conversion of the intermediate richterite into enstatite, $\mathrm{Cu}(\mathrm{II})$ is bound in compressed rhombic sites of the enstatite with $\mathrm{a} \mathrm{d}_{\mathrm{z}}{ }^{2}$ ground state and in axial sites.

(4) The present results suggest that investigating traces of $\mathrm{Cu}(\mathrm{II})$, which are characteristic of natural environments, can provide insights into the conversion processes in high-temperature geochemical systems such as contact metamorphism.

\section{ACKNOWLEDGMENTS}

The authors are grateful to Lorenz Meier (Zürcher Hochschule Winterthur) for assistance with sample preparation, Katja Emmerich (Forschungzentrum Karlsruhe) for the DSC-TG analysis, Michael Plötze (ETH Zürich) for the clay analysis. They also thank Inés Garcia Rubio (ETH, Zurich) for her help with the low-temperature data 
acquisition, Rob Hunter (University of St Andrews) for the Q-band measurements, and Josef Granwehr (University of Nottingham) for critical discussion of the EPR data. This work was supported by ETH research grant TH 02296.

\section{REFERENCES}

Billing, D.E., Dudley, R.J., Hathaway, B.J., and Tomlinson, A.A.G. (1971) Single-crystal electronic and electron spin resonance spectra of di-chloroaquo(2,9-dimethyl-1, 10-phenantroline)copper(II). Journal of the Chemical Society (A), 691-696.

Bilton, M.S., Gilson, T.R., and Webster, M. (1972) Vibrational-spectra of some chain type silicate minerals. Spectrochimica Acta, 28A, 2113-2119.

Boukerrou, A., Duchet, J., Fellahi, S., and Sautereau H. (2006) Effect of geometry and surface properties of silicates on nanostructuration of suspension in precursors of an epoxy/ amine network. Journal of Applied Polymer Science, $\mathbf{1 0 2}$, 1380-1390.

Chipera, S.J. and Bish, D.L. (2002) Thermal evolution of fluorine from smectite and kaolinite. Clays and Clay Minerals, 50, 38-46.

Clementz, D.M., Pinnavaia, T.J., and Mortland, M.M. (1973) Stereochemistry of hydrated copper (II) ions on the interlamellar surfaces of layer silicates. An electron spin resonance study. The Journal of Physical Chemistry, 77, $196-200$.

Decarreau, A. (1980) Experimental crystallogenesis of Mgsmectite - hectorite, stevensite. Bulletin de Minéralogie, 103, 579-590.

Decarreau, A. (1981) Crystallogenesis at low-temperature of trioctahedral smectites by aging silico-metallic co-precipitates of formula $\left(\mathrm{Si}(4-\mathrm{x}) \mathrm{Al}_{\mathrm{x}}\right) \mathrm{M}_{3}^{2+} \mathrm{O}_{11}, \mathrm{nH}_{2} \mathrm{O}$, where $\mathrm{x}$ changes from 0 to 1 , and $\mathrm{M}^{2+}$ is $\mathrm{Mg}, \mathrm{Ni}, \mathrm{Co}, \mathrm{Zn}, \mathrm{Fe}, \mathrm{Cu}, \mathrm{Mn}$. Comptes Rendus de Academie des Sciences de Paris Serie II, 292, 61-64.

Farmer, V.C. (1974) The Infrared Spectra of Minerals. Monograph 4, Mineralogical Society, London.

Gadsen, J.A. (1975) Infrared Spectra of Minerals and Related Inorganic Compounds. Butterworth, London.

Gehring, A.U. and Hofmeister, A.M. (1994) The transformation of lepidocrocite during heating: a magnetic and spectroscopic study. Clays and Clay Minerals, 42, 409-415.

Gehring, A.U., Fry, I.V., Luster, J., and Sposito, G. (1993) Vanadium(IV) in multimineral lateritic saprolite: a thermoanalytical and spectroscopic study. Soil Science Society of America Journal, 57, 868-873

Gibbs, G.V., Miller, J.L., and Shell, H.R. (1962) Synthetic fluor-magnesio-richterite. American Mineralogist, 47, $75-82$

Green, J.M., MacKenzie, K.J.D., and Sharp, J.H. (1970) Thermal reactions of synthetic hectorite. Clays and Clay Minerals, 18, 339-346.

Granquist, W.T. and Pollack, S.S. (1959) A study of the synthesis of hectorite. Proceedings of the National Conference on Clays and Clay Minerals, 8, 150-169.

Jones, J.P.E, Angel, B.R., and Hall, P.L. (1974) Electron spin resonance studies of doped synthetic kaolinite. II. Clay Minerals, 10, 257-270.

Karakassides, M.A., Arvaiova, B., Bourlinos, A., Petridis, D., and Komadel, P. (1999) Location of $\mathrm{Li}(\mathrm{I}), \mathrm{Cu}(\mathrm{II}), \mathrm{Cd}(\mathrm{II})$ in heated montmorillonite: evidence from secular reflectance infrared and electron spin resonance spectroscopies. Journal of Materials Chemistry, 9 1553-1558.

Kloprogge, J.T., Komarneni, S., Yanagisawa, K., Frost, R.L., and Fry, R. (1998) Infrared study of some synthetic and natural beidellites. Journal of Materials Science Letters, $\mathbf{1 7}$, $1853-1855$.

Klug, H.P. and Alexander, L.E. (1975) X-ray Diffraction Procedures. J. Wiley, New York.

Luca, V., Chen, X., and Kevan, L. (1991) Characterization of copper(II)-substituted synthetic fluorohectorite clay and interaction with adsorbates by electron spin resonance, electron spin echo modulation and infrared spectroscopies. Chemisty of Materials, 3, 1081-1087.

Mandair, A.P.S., Michael, J.P., and McWhinnie, W.R. (1990) ${ }^{29} \mathrm{Si}$ MASNMR investigations of the thermochemistry of Laponite and hectorite. Polyhedron, 9, 517-525.

Meads, R.E. and Malden, P.J. (1975) Electron spin resonance in natural kaolinites containing $\mathrm{Fe}^{3+}$ and other transition metal ions. Clay Minerals, 10, 313-345.

Mohanty, T., Mishra, N.C., Bhat, S.V., Basu, P.K., and Kanjilal, D. (2003) Dense electronic excitation induced defects in silica. Journal of Physics D: Applied Physics, 36, $3151-3155$

Mosser, C., Michot, L.J., Villieras, F., and Romeo, M. (1997) Migration of cations in copper(II)-exchanged montmorillonite and Laponite upon heating. Clays and Clay Minerals, 45, 789-802.

Poonguzhali, E., Srinivasan, R., Ravikumar, R., Chandrasekhar, A.V., Reddy, B.J., Reddy, Y.P., and Sambasiva Rao, P. (2002) Single crystal EPR and optical studies of $\mathrm{Cu}$ (II) doped zinc ammonium phosphate hexahydrate: A case of rhombic distortion. Physica Scripta, 66, 391-394.

Rao, P.S., Viswanath, A.K., and Subramanian, S. (1992) EPR of dynamic Jahn-Teller distortion in $\mathrm{Cu}(\mathrm{II})$ doped magnesium Tutton's salt. Spectrochimica Acta, 48A, 1745-1747.

Schosseler, P.M. and Gehring, A.U. (1996) Transition metals in Llano vermiculite samples: An EPR study. Clays and Clay Minerals, 44, 470-478.

Spagnuolo, M., Martinez, C.E., Jacobson, A.R., Baveye, Ph., McBride, M., and Newton, J. (2004) Coprecipitation of trace metal ions during the synthesis of hectorite. Applied Clay Science, 27, 129-140.

Stadelmann, P.A. (1987) EMS - a Software Package for Electron-Diffraction Analysis and Hrem Image Simulation in Materials Science. Ultramicroscopy 21, 131-145.

Stoll, S. and Schweiger, A. (2006) EasySpin, a comprehensive software package for spectral simulation and analysis in EPR. Journal of Magnetic Resonance, 178, 42-55.

Strens, R.G.J. (1974) The common chain, ribbon and ring silicates. Pp. 305-330 in: The Infrared Spectra of Minerals (V.C. Farmer, editor). Monograph 4, Mineralogical Society, London.

Tarantino, S.C., Ballaran, T.B., Carpenter, M.A., Domeneghetti, M.C., and Tazzoli, V. (2002) Mixing properties of the enstatite-ferrosilite solid solution: II. A microscopic perspective. European Journal of Mineralogy, 14, $537-547$.

Wertz, J.E. and Bolton, J.R. (1972) Electron Spin Resonance. McGraw-Hill, New York. 